\title{
DÜBLIN
}

Technological University Dublin

ARROW@TU Dublin

2013-6

\section{The Quantification Of Wind Turbulence By Means Of The Fourier Dimension}

\author{
Thomas Woolmington \\ Technological University Dublin, thomas.woolmington@tudublin.ie \\ Keith Sunderland \\ Technological University Dublin, keith.sunderland@tudublin.ie \\ Jonathan Blackledge \\ Technological University Dublin, jonathan.blackledge@tudublin.ie
}

See next page for additional authors

Follow this and additional works at: https://arrow.tudublin.ie/engscheleart

Part of the Other Engineering Commons

\section{Recommended Citation}

Woolmington, T., Sunderland, K., Blackledge, J., Conlon, M. : The Quantification Of Wind Turbulence By Means Of The Fourier Dimension, IET Digital Library - 24th IET Irish Signals and Systems Conference (ISSC 2013)

This Conference Paper is brought to you for free and open access by the School of Electrical and Electronic Engineering at ARROW@TU Dublin. It has been accepted for inclusion in Conference papers by an authorized administrator of ARROW@TU Dublin. For more information, please contact arrow.admin@tudublin.ie, aisling.coyne@tudublin.ie,gerard.connolly@tudublin.ie.

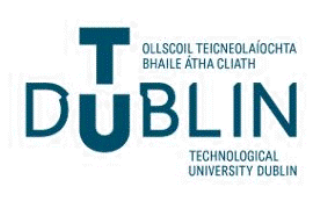




\section{Authors}

Thomas Woolmington, Keith Sunderland, Jonathan Blackledge, and Michael Conlon 


\title{
The Quantification Of Wind Turbulence By Means Of The Fourier Dimension
}

\author{
T. Woolmington, K. Sunderland, J. Blackledge, M. Conlon
}

School of Electrical and Electronic Engineering,

Dublin Institute of Technology

\begin{abstract}
Signal Processing within the frequency domain has long been associated with electrical engineering as a means to quantify the characteristics of voltage/current waveforms. Historically, wind speed data (speed/direction) have been captured and stored as statistical markers within a time series description. This form of storage, while cumbersome, is applicable in wind regimes that are relatively laminar. In urban environments, where the associated topographies and building morphologies are heterogeneous, wind speeds are highly turbulent and chaotic. In such environments and with particular reference to wind energy, time series statistics are of limited use, unless the generic probability distribution function (PDF) is also considered. Furthermore, the industry standard metric that quantifies the turbulent component of wind speed, Turbulence Intensity (TI), is computationally cumbersome and resource intensive. An alternative model to quantify turbulence is proposed here. This paper will describe how Fourier dimension modelling $\left(D_{f}\right)$, through linkage with the Weibull probability density function, can quantify turbulence in a more efficient manner. This model could potentially be developed to facilitate urban wind power prediction and is relevant to the planning and development considerations within the built environment.
\end{abstract}

Keywords - Small wind turbines, urban environments, turbulence, fractals, turbulence intensity, and Weibull distributions

\section{INTRODUCTION}

With the recognition of global population migration toward cities and the resultant demand for energy within these environments, the applicability of renewable technologies therein is increasingly topical. Transmission losses within electrical networks are forcing engineers and planners to consider the positioning of wind turbine technologies within urban centres. This presents new challenges to the already limited understanding of how urban topology/heterogeneity affects micro wind technologies. A related issue is that of the classification of turbulence and its adverse effects on the power performance of turbines. A turbulence intensity metric was proposed as a means to quantify turbulence in IEC 61400-2. However it is becoming evident that there are issues with this metric. This paper will question the suitability of the TI metric within an urban context and then bench mark a new metric called the Turbulent Fourier Dimension $\left(\mathrm{T}_{\mathrm{Df}}\right)$ against it as an alternative means to quantify turbulence in horizontal wind signals taken from two sites (urban and suburban) in Dublin Ireland.

\section{(a) Measurement sites}

Observations are made at two urban locations in Dublin, Ireland. Dublin City Council Buildings, in
Marrowbone Lane, located in Dublin 8 $\left(53^{\circ} 20^{\prime} 15.96^{\prime \prime} \mathrm{N}, 6^{\circ} 17^{\prime} 10.27^{\prime \prime} \mathrm{W}\right)$ and St. Pius X National (Girls) School, located in Terenure, Dublin $6 \mathrm{~W}$ (5320'15.96'”N, 6 ${ }^{\circ} 18^{\prime} 19.02^{\prime}$ 'W). Both the Marrowbone and St Pius sites will be hereafter referred to as $U R B 1$ and $S U B 2$ respectively.

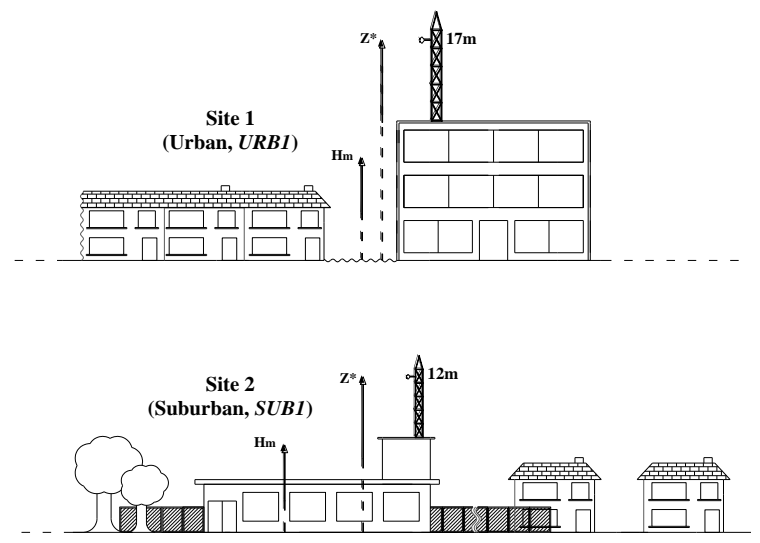

Figure. 1: Relative context of wind observation locations. Site 1 mixed topography of low and high rise developments. Site 2 low rise development with increasing amounts of similar height vegetation. 
URB1 is located closer to the city centre than SUB 2 and would therefore be expected to be more urbanized with a higher associated roughness length $\left(\mathrm{z}_{0}\right)$. This site is characterised by a higher building density compared to SUB 2, which has a much lower concentration of buildings. As URB 1, is closer to the city centre, the building demographic consists of office blocks and high-rise residential building. Buildings in the area often reach heights of $20 \mathrm{~m}$ and beyond, with some reaching $25 \mathrm{~m}$, with topographical complexities located at all angles relative to the anemometer location.

SUB2 on the other hand, has a more consistent building morphology and the anemometer is surrounded by a relatively lower average building height that consist mostly of two-storey residential buildings and vegetation which is also at similar heights.

At URB 1, the anemometer is again located on a rooftop and is mounted on an aerial mast, but at a height of $17 \mathrm{~m}$ above local ground level. The anemometer at SUB 2 is located on the roof of a school on an upright self-supporting mast at a height of $12 \mathrm{~m}$ above local ground level at the boundary between the surface roughness and inertial sublayers. The installation height was once again carefully chosen to be at the boundary between the surface roughness and inertial sub-layers. For both sites, measurements were taken consistently from $4 / 4 / 2012$ to $15 / 5 / 2012$. At both sites, high-resolution wind speed measurements were taken with a Campbell Scientific CSAT3 three-dimensional sonic anemometer [1]. The observations are at $10 \mathrm{~Hz}$ at an associated resolution-between $0.5-1.0 \mathrm{mms}^{-1}$, with data-including-date and-timestamp, wind-speed, wind-direction and standard deviation. The CSAT3 measures wind speed on three non-orthogonal axes. The system employs a right handed orthogonal coordinate system with the sensor head pointing in the negative ' $-\mathrm{x}$ ' direction $(-\mathrm{u})$. Three orthogonal wind components, which relate to the three dimensions in space, are each measured. Wind entering straight into the anemometer is from the $+\mathrm{x}$ direction, $u$; wind approaching from the left of the anemometer is from the $+\mathrm{y}$ direction, $v$; and wind advancing upwards from the ground is from the $+\mathrm{z}$ direction, $w$. Thus, effectively, the northerly component of the wind is $u$, the easterly component of the wind is $v$, and the vertical component of the wind is $w$.

\section{BACKGROUND AND METHODOLOGY (a) Turbulence}

Urban wind regimes are characterised as having low wind speeds with more turbulent flow which result in limited energy realisation. Research has shown that the lower mean speeds are linked to the higher surface roughness lengths $\mathrm{z}_{0}$ prevalent in urban environments [2-4]. The manifestation of turbulence however, is less well understood.

Turbulent flows can be described as those in which the fluid velocity varies significantly and irregularly in both position and time [5]. While turbulently fluctuating flow impacts directly on the design of wind turbines, it also influences the productivity of turbines - particularly in areas of complex morphologies. Turbulence Intensity (TI) is the most common metric describing the turbulent effect. Heretofore, the approach has been used to develop descriptions of turbulence in terms of statistical properties [6]. TI is defined in [7] as "the ratio of wind speed standard deviation to the mean wind speed, determined from the same set of measured data samples of wind speed, and taken over a specified time" and should actually be considered as the standard deviation of the longitudinal wind speed $\sigma_{\mathrm{u}}$ normalised with the mean wind speed $\bar{u}(1)$.

$$
T I=\frac{\sigma_{\mathrm{u}}}{\bar{u}}
$$

The complex morphology experienced in an urban environment results in a modified flow and turbulent structure in the urban atmosphere in contrast to the flow over 'ideal or homogenous' surfaces [8].

With respect to the impact on the power output of wind turbines subjected to turbulence, the majority of the available research considers utility scale systems with capacities in MW ranges [9-12]. In $[10,11]$, the effect turbulence intensity has on the power curve of a turbine is summarised by Figure. 2 . High TI contributes to increased output power from a turbine at moderate wind speeds (cut-in), whereas low TI results in reduced output power at rated wind speed.

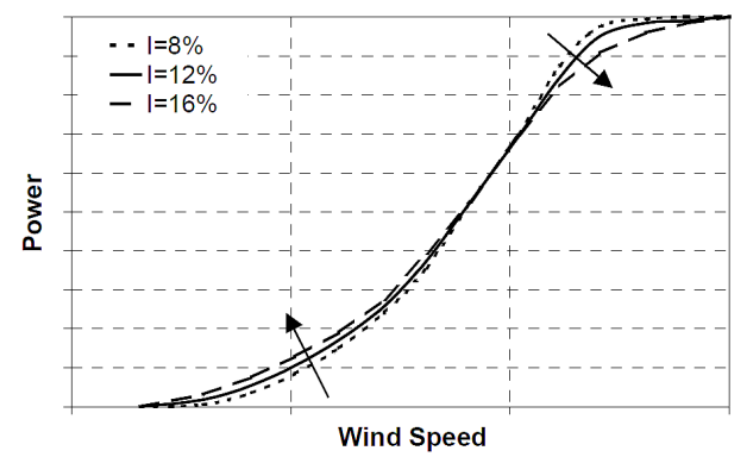

Figure 2: Typical Effects of Turbulence on Power Curves [10]

Lubitz [13], considered the influence of turbulence on energy production from a Bergey XL.1 
small wind turbine. His $1 \mathrm{~Hz}$ observations were also in agreement with [10, 11]. More specifically, his analysis found that low TI consistently results in reduced power output $(-2 \%)$ between $4 \mathrm{~m} / \mathrm{s}$ and $7 \mathrm{~m} / \mathrm{s}$, whereas high TI contributes to increased power output (up to $+4 \%$ ), over the same speed range.

However consider a simulated wind speed scenario as presented in Figure. 3. It becomes evident that the TI model does not take cognisance of trends within the 10 minute wind speed. Consider a gradually rising wind speed from $2 \mathrm{~m} / \mathrm{s}$ to $10 \mathrm{~m} / \mathrm{s}$ over a 10 minute period. The mean wind speed is $4 \mathrm{~m} / \mathrm{s}$ and the standard deviation of $+/-1.24 \mathrm{~m} / \mathrm{s}$. This gives a TI of $31 \%$ but should this be classified as turbulence?

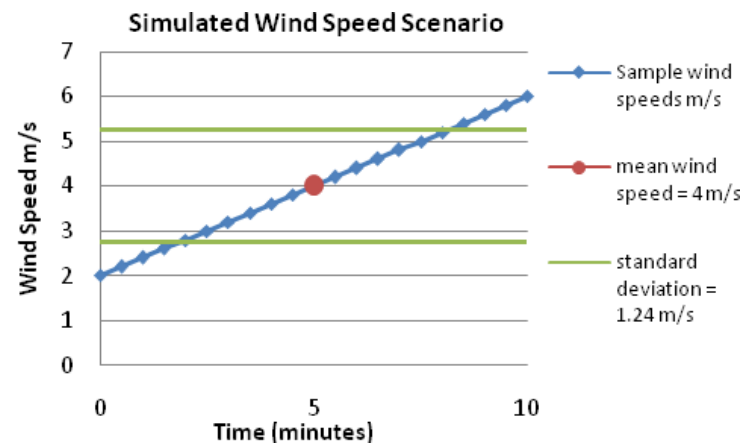

Figure. 3 Simulated wind speed model (Note: $\mathrm{TI}=31 \%$ and $\left.\mathrm{D}_{\mathrm{f}}=1\right)$

(b)

The Fourier Dimension

Fractal analysis has long been associated with self symmetry held within digital images [14]. This self symmetry has been used in the past to recreate a "natural" look for computer generated images in order to make them appear more lifelike. Self symmetry may also be present in numerical time series and as a result an associated fractal dimension of the series can be obtained.

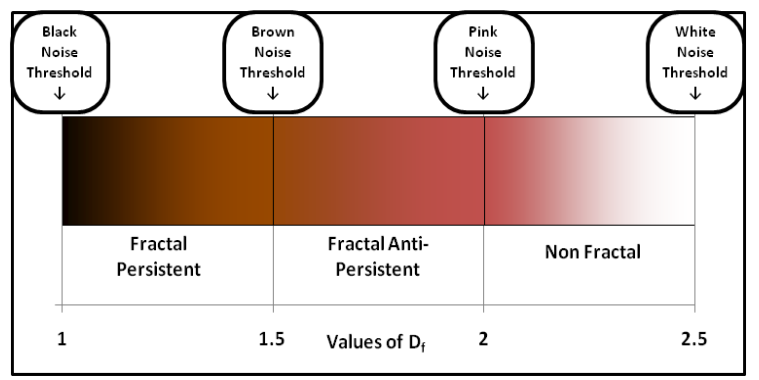

Figure 4: Noise spectrum including fractal components

Fractal analysis however is limited by the bounds of fractal theory i.e. that for a signal to be considered to be a true 1D fractal, the Fourier dimension $\left(D_{f}\right)$ should be classified within the bounds of 1 and 2. For instance Mandlebrot has demonstrated that a $D_{f}=1.5$ can be used to classify classical Brownian motion of particle movement suspended in a liquid [15]. Fractal time series below this threshold of $D_{f}=1.5$ as can be shown to be persistent in nature (there is a high likelihood that subsequent points will follow the trend of previous points) Also values with $D_{f}$ greater than 1.5 and less than 2 are deemed to be anti-persistent and there is a high likelihood that the next value in a time series will revert back on itself [16].

If we consider values $D_{f}>2$, it becomes apparent that such signals can no longer be classified as fractal, but these signals could be classified under noise theory. $\mathrm{D}_{\mathrm{f}}>2$ can be considered as pink noise getting progressively closer to white noise at $\mathrm{D}_{\mathrm{f}}=$ 2.5 , where no discernable trend within a signal can be found.

Consider a series of 1024 random numbers $\left(\mathrm{n}_{\mathrm{x}}\right)$ between $0-1$ subjected to the following convolution $(\otimes)$ in the frequency domain.

$$
\left[u_{x}(t)\right]=\frac{1}{t^{1-q / 2}} \otimes \mathrm{t}\left[n_{x}(t)\right]
$$

Where: $D_{\mathrm{f}}($ Fourier Dimension $)=(5-q) / 2$

Frequency domain equivalent with $i$ indexing filter

$$
\left[U_{x}(\omega)\right]=\frac{1}{(i \omega)^{q / 2}}\left[n_{x}(\omega)\right]
$$
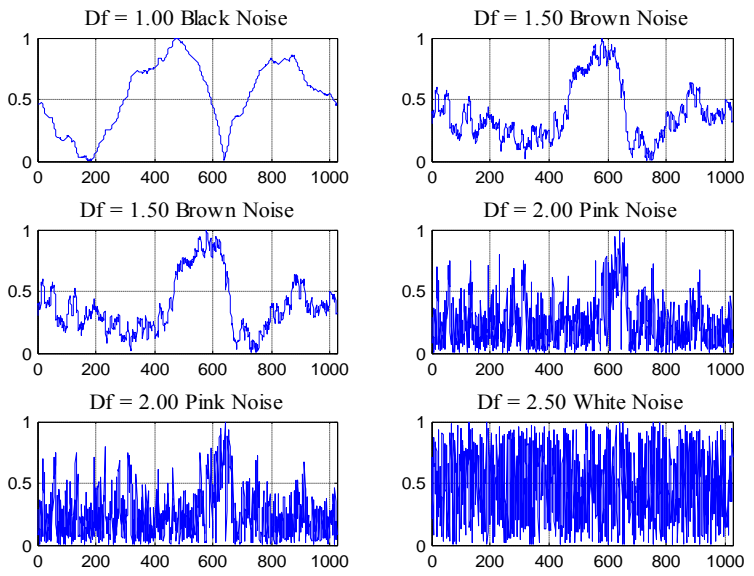

Figure 5: Simulated noise signals with results for 1024 random numbers

In considering the corollary to this approach, the fractal component can be obtained from a noisy signal. In essence such an approach is analogous to obtaining measurement of turbulence within a sampled time period.

\section{(c) Quantification Procedure}

\section{Longitudinal Turbulence Intensity}

The longitudinal Turbulence intensity was calculated in accordance with IEC 61400-2. It is intended that this method be used as a reference method to a proposed new method called Turbulent Fourier Dimension $\left(\mathrm{T}_{\mathrm{Df}}\right)$. 
The measurement of longitudinal turbulence intensity at low wind speeds can frequently result in values larger than $100 \%$ due to the asymptotic nature of the describing in formula (1). As a consequence, this makes the current turbulence metric, TI, problematic, particularly in urban areas. Firstly it is generally accepted that the standard deviation of wind speeds in an urban area could be large due to a increased turbulence. Secondly the average wind speed is considerably lower than that of laminar wind flow (such as what is found at rural sites) due to the increased surface roughness. The net result is that the $\mathrm{TI}_{\text {Long }}$ gets asymptotically large as the mean wind speed approaches zero as a consequence of the mean wind speed being the divisor in the TI formula (1). The implication, therefore, is that $\mathrm{TI}_{\text {long }}>100 \%$ are truncated from the data set.

\section{Quantification of Fourier Dimension}

Theoretically the fractal component of any signal should be relevant at all magnifications of a given signal and therefore the frequency of the sample rate should not matter. However the assessment method relies on the Fourier transform, which implies a full frequency spectrum range. Therefore, an inherently large amounts of datums in a given sample subset are required in order to achieve reasonable accuracy. This also implies that a large sample size is required if an accurate response is to be achieved. The current accepted TI model is based on a 10 minute sampling period and it was deemed prudent to use this as a benchmark measurement. This resulted in a sample size of 6000 datums $(10$ minutes at $10 \mathrm{~Hz})$.

Ten minute interval data sets of Cartesian coordinates were processed as follows:

i. Firstly the longitudinal wind speed is calculated in accordance with IEC 61400-2. In essence this is the polar wind speed vector of horizontal wind speed components $\mathrm{x}$ and $\mathrm{y}$. The resultant is then cosine corrected to the mean 10 minute wind direction for that ten minute interval giving the longitudinal wing speed

$$
\begin{gathered}
U_{\text {Polar }}=\sqrt{\left(U_{x}\right)^{2}+\left(U_{y}\right)^{2}} \\
U_{\text {Long }}=\operatorname{Cos}\left(\theta_{10 \text { min mean }}-\theta_{\text {Datum }}\right)
\end{gathered}
$$

Where $\mathrm{U}_{\mathrm{x}}, \mathrm{U}_{\mathrm{y}}$ are cartesian wind speeds in the horizontal plane for a particular datum.

ii. The Fast Fourier Transform (fft) is then applied to the 6000 entries of horizontal wind speed. Only terms from $\mathrm{n}(2)$ to term $\mathrm{n} / 2$ are considered (Note; The DC component, $\mathrm{n}(1)$, as the average wind speed was removed. The optical form of the power spectrum is symmetrical and as a result only terms up to $n / 2$ are considered.) The $\log$ of the power spectrum as well as the log of the magnitude of frequency was then obtained. These two components were then represented on a graph with the associated linear regression of the points providing the slope component $\mathrm{m}$, which in this instance corresponds to the $\mathrm{q}$ component from (2).

$$
D_{f}=\frac{(5-q)}{2}
$$

A self validation scenario to determine the accuracy of the calculation method stated above was carried out using 1000 samples of 6000 datums with known $\mathrm{D}_{\mathrm{f}}$. It was found that all responses were within $3.48 \%$ of the true $D_{f}$. This would imply a that a maximum error due to rounding and sample size of circa $3.5 \%$ exists with this method. However it must be noted that the simulated data is pure fractal noise and this may not be indicative of error values associated with real world field measurements.

\section{RESULTS}

Data was filtered to the following levels due to $\mathrm{TI}>100 \%$.

\begin{tabular}{|l|l|l|l|}
\hline \multicolumn{1}{l}{} & \multicolumn{1}{c}{$\begin{array}{c}\text { Origional } \\
\text { Data }\end{array}$} & $\begin{array}{c}\% \text { Bad } \\
\text { Data }\end{array}$ & $\begin{array}{c}\text { Filtered } \\
\text { data }\end{array}$ \\
\hline URB1 Marrowbone & 5568 & 0.233 & 5555 \\
\hline SUB2 St Pius & 5746 & 0.313 & 5728 \\
\hline
\end{tabular}

Figure. 6 and Figure. 7 illustrate time series results of the calculated $\mathrm{TI}$ and $\mathrm{T}_{\mathrm{Df}}$ followed by correlation scattergrams of $\mathrm{TI}$ verses $\mathrm{T}_{\mathrm{Df}}$ - for all filtered 10 minute samples - with respect to both sites. The results for the first site, URB 1 (Marrowbone) as illustrated in Figure. 6, shows some evidence of trending but due to the low wind speed, the TI metric illustrates evidence of stochastic anomalies (derived as a result of the division by numbers approaching zero). As a result there is virtually no correlation $\left(\mathrm{R}^{2}\right.$ $=0.07831)$. While this could be regarded as problematic, it is important to remember that the TI metric has issues with mean wind speeds close to zero, as previously described. Therefore a more valid metric would have a consistent correlation for a highly turbulent site with low mean wind speed. It is also noted that the $\mathrm{T}_{\mathrm{Df}}$ model firmly keeps all values within the range of 1.5 to 2.5 .

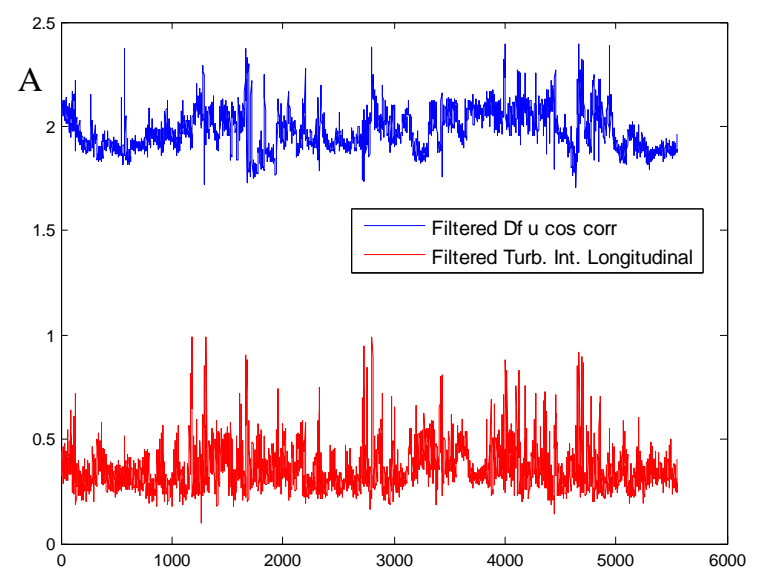




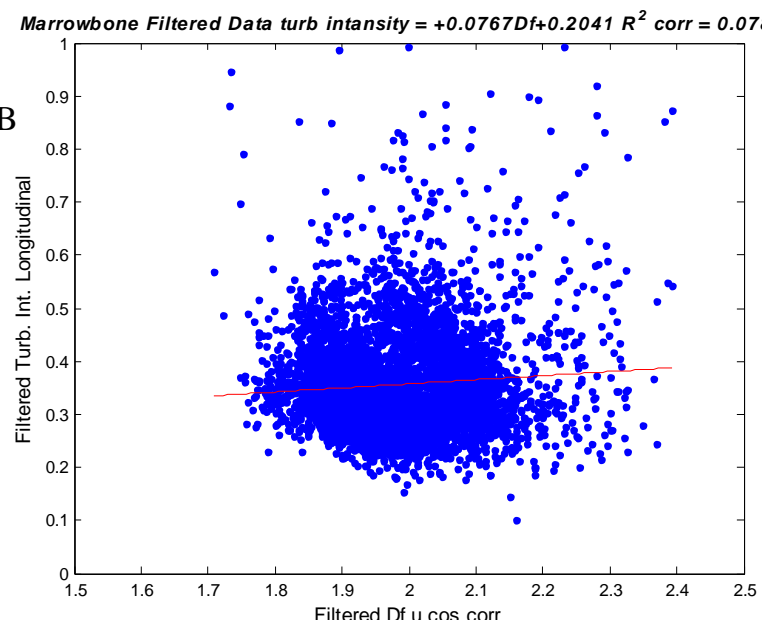

Figure. 6: Results for URB1. 6A Timeseries for all samples ( TI and $\left.\mathrm{T}_{\mathrm{Df}}\right) 6 \mathrm{~B}$ Scattergram Linear correlation gives $\mathrm{TI}=$ $0.0767 \mathrm{~T}_{\mathrm{Df}}-0.2041$. Note: considerable outliers present due to the different approaches of quantifying turbulence.
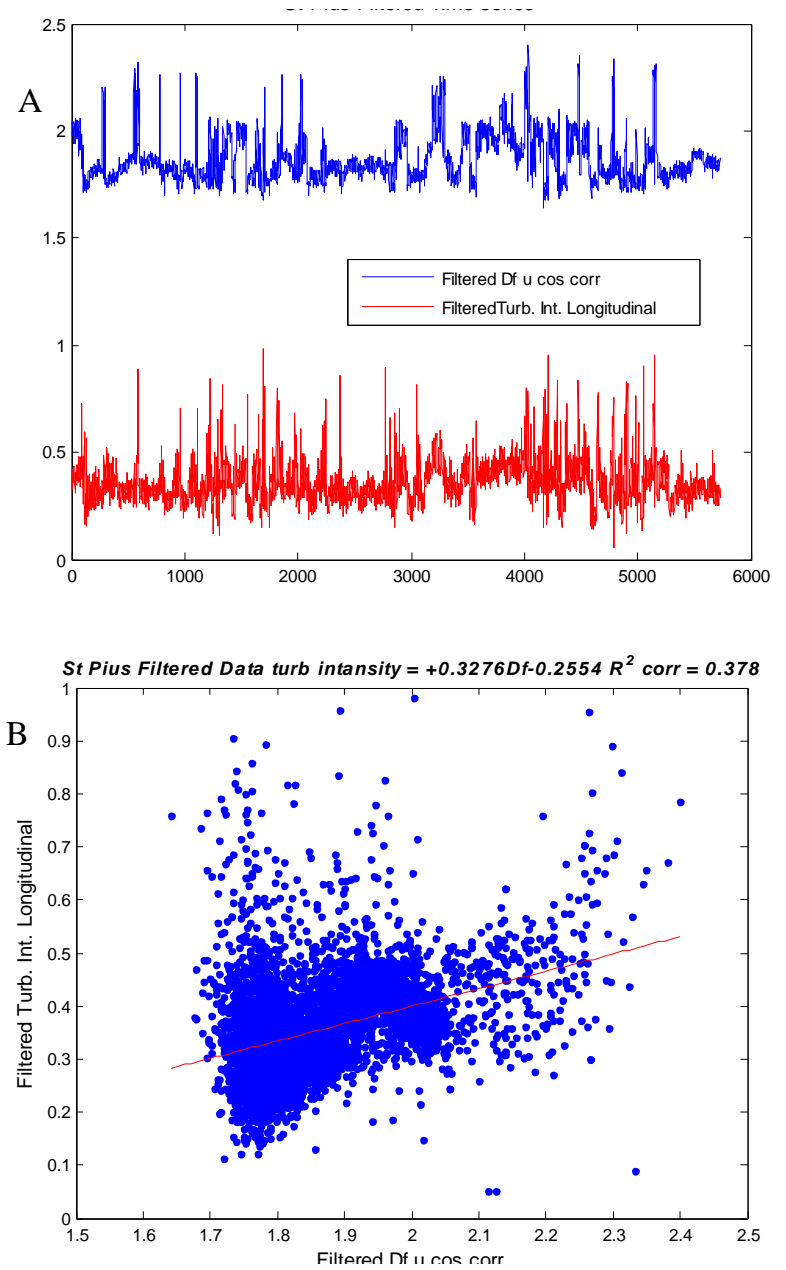

Figure. 7: Results for SUB2. 7A Timeseries for all samples (TI and $\left.\mathrm{T}_{\mathrm{Df}}\right)$ 7B Scattergram Linear correlation gives $\mathrm{TI}=$ $0.3276 \mathrm{~T}_{\mathrm{Df}}-0.2554$. Note: considerable outliers present due to the different approaches of quantifying turbulence. Considerably more correlation present than in URB1.
In the second site, SUB2 (St Pius) as illustrated in Figure.7, there is increased evidence of trending or consistencies over certain sections of the time series. While this appears in some sections, it is also evident that there is also considerable non correlation throughout. Once again the TI metric has considerable stochastic instances that do not appear to the same extent in the $\mathrm{T}_{\mathrm{Df}}$ model. It is evident that there is considerably more correlation between the two metrics for the SUB2 (St_Pius) site $\left(\mathrm{R}^{2}=0.378\right)$. It is also evident that a large portion of the data could be made to fit a linear correlation pattern (admittedly with large error bands).

It is notable that the TI metric is also prone to creating excessively high anomalies. Such representations are manifested as a result of a simple gust in a low mean wind speed sample. This can dramatically effect the standard deviation for the 10 minute sample with a knock-on effect being a (much) larger reading than would be expected. (Note; A similar situation in reverse could happen using cup type anemometry at low wind speeds where the wind speed is not sufficient to turn the anemometer head).

While the $\mathrm{T}_{\mathrm{Df}}$ model is also prone to anomalies, said effects are minimised due to the fact that the $\mathrm{T}_{\mathrm{Df}}$ model is derived in the frequency domain. The net result is that with low mean wind speeds and the high likelihood of gusting effects, a "generic" correlation between the TI and $\mathrm{T}_{\mathrm{Df}}$ models in turbulent urban environments is not likely. However it is quite probable that there would be more correlation in more laminar (less turbulent) air flows at higher mean wind speeds.

Furthermore irrespective of the models being considered here, a simple mean value of the whole data set is virtually useless as a means to quantify the turbulence on a site. A possible justification for this might be the influence of upstream obstacles. An obstacle upstream of the measurement device will create a different turbulent pattern based on the wind speed for the given sample period. Consider the wake pattern left behind a speed boat at low speed compared to that at high speed. It not only has a different wake length but a different pattern within the wake itself.

That said, if both models are viewed in isolation with the addition of binned wind speeds it may be possible to determine if one method is better than the other in an urban context.

As evident in Figure 8 The TI metric does not appear to give a clear indicator as to which site is more turbulent. This is a major drawback of this model. It is likely that the asymptotic effect at lower wind speeds would lead one to assume that the URB 
1 site (Marrowbone) is more turbulent but how can the model explain that the suburban site is more turbulent than the Urban site for over half of the range of wind speeds.

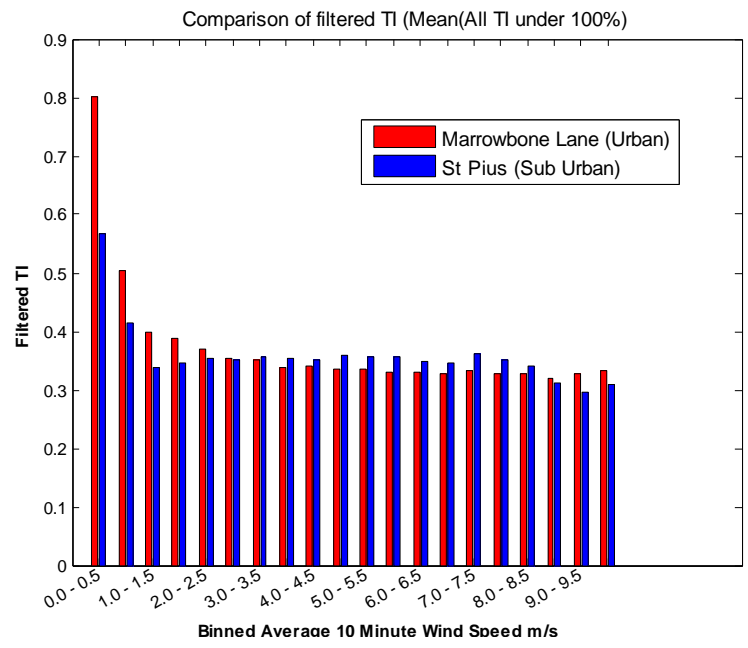

Figue. 8: Mean Filtered TI over a binned wind speed range for both sites.

In Figure 9 The $\mathrm{T}_{\mathrm{Df}}$ model gives a clear indication that URB 1 (Marrowbone) is more turbulent when compared to the SUB 2 (St Pius) site across the vast majority of wind speed bins. It is also envisaged that this could be used as a means to quantify a generic classification of a site for the purpose of site selection based on turbulence.

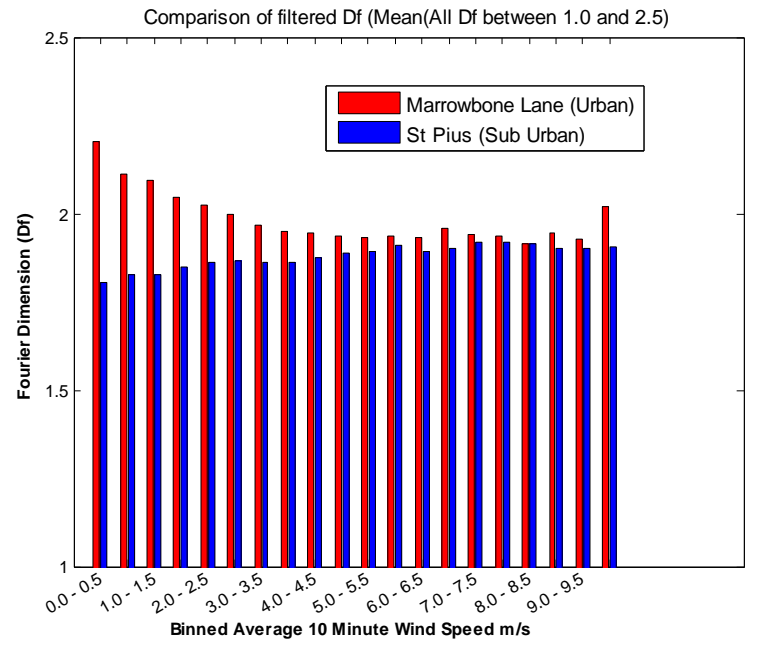

Figure. 9: Mean Filtered Df over a binned wind speed range for both sites.

\section{DISCUSSION \&CONCLUSIONS}

It is evident that the use of the TI metric is problematic in an urban context, but it remains the industry norm in considering small wind turbines in urban environments. The $\mathrm{T}_{\mathrm{Df}}$ model, while it is less computationally demanding, currently has no application in the area of power prediction. Further research is required if the $T_{D f}$ metric is to offer holistically improvements on the TI model in terms of dealing with turbulence in an urban wind resource context. That said there are alternative routes that tie the $\mathrm{D}_{\mathrm{f}}$ model to statistical PDF (Probability Distribution Function) models of interest. Fractal mathematics is emerging as a means to quantify non euclidean measurements in a range of applications from microbiology to cartography. As such there are mathematical advances being made in this area that are awaiting an application. One advancement that may prove useful in the turbulence modelling is with respect to application of the Weibull PDF [17]. All Weibull distributions are bounded by $\mathrm{D}_{\mathrm{f}}$ values in the range;

$$
0 \leq D_{f} \leq 3
$$

An area of future research is with respect to classifying Weibull PDF in terms of $D_{f}$, based on the fact that all Weibull distributions can be classified as having a specific $D_{f}$. Wind speeds have a long 'tradition' of being classified as having a Weibull PDF and these two specific forms of mathematics can be merged to provide a viable means to predict turbine power performance. It is intended to employ the following strategy in this regard:

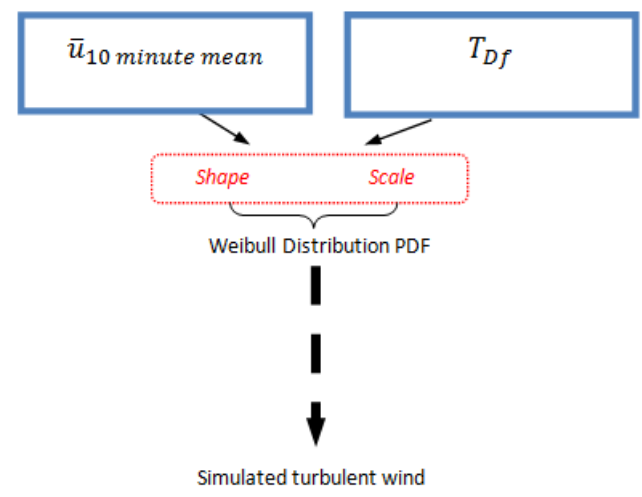

Figure. 10: Proposed future Methodology for power prediction.

This research (outlined in Figure 10) will focus on the possibility of power prediction based solely on the $\mathrm{T}_{\mathrm{Df}}$ and mean wind speed. It is hoped that a model can be developed that can accurately predict the wind resource in a turbulent site thus furthering the likely implementation of turbine technologies in urban environments.

\section{ACKNOWLEDGEMENTS}

The wind velocity data is graciously provided by Dr. Rowan Fealy, of the National University of Ireland, Maynooth (NUIM) and Dr. Gerald Mills, University College Dublin,(UCD) through the Dublin Urban Boundary Layer Experiment (DUBLex) collaboration. 


\section{REFERENCES}

[1] Campbell Scientific. (2011, CSAT3 , 3-D Sonic Anemometer. Available: http://www.campbellsci.com/csat3

[2] Lars Landberg, et al., "Wind Resource Estimation - An Overview," Wind Energy, vol. 6, pp. 261-271, 2003.

[3] S. L. Walker, "Building mounted wind turbines and their suitability for the urban scale-A review of methods of estimating urban wind resource," Energy and Buildings, vol. 43, pp. 1852-1862, 2011.

[4] Landberg L., et al., "Wind Resource Estimation - An Overview," Wind Energy, vol. 6, pp. 261-271, 2003.

[5] Pope S. B., Turbulent Flows: Cambridge University Press, 2000.

[6] Burton T., et al., Wind Energy Handbook: Wiley \& Sons Ltd., 2001.

[7] IEC, "International Standard 61400-2. Wind Turbines Part 2: Design requirements for small turbines," ed, 2006.

[8] Rotach M.W., "Profiles of turbulence statistics in and above an urban street canyon," Atmospheric Environment, vol. 29, pp. 1473-1486, 1995.

[9] Rossen A. and Sheinman Y., "The average output power of a wind turbine in a turbulent wind," Wind Engineering \& Industrial Aerodynamics, vol. 51, pp. 287-302, 1994.

[10] Langreder W., et al., "Turbulence Correction for Power Curves," presented at the EWEC, London, 2004.

[11] Tindal A., et al., "Site-specific adjustments to wind turbine power curves," presented at the AWEA Wind Power Conference, Houston, 2008.

[12] Wagner R., et al., "Simulation of shear and turbulence impact on wind turbine power performance,," Riso DTU (National Laboratory for Sustainable Energy), 2010 .

[13] Lubitz W. D., "Impact of ambient turbulence on performance of a small wind turbine," Linkoping, Sweden, 2011.

[14] M. J. Turner, et al., Fractal Geometry in Digital Imaging, 1st ed. London: Academic Press, 1998.

[15] B. B. Mandelbrot, The fractal geometry of nature. San Francisco: W.H. Freeman, 1982

[16] Hastings H. and Sugihara G., Fractals - a user's guide for the natural sciences. Oxford: Oxford University Press, 1993.

[17] W. Brown and K. Wohletz, "Derivation of the Weibull distribution based on physical principles and its connection to the Rossin-Rammler and lognormal distributions," Journal of Applied Physics, vol. 78, pp. 2758-2763, 1995. 